\title{
Mechanical Properties and Shrinkage of Ultrahigh-Performance Concrete Containing Lithium Carbonate and Nano-Calcium Carbonate
}

\author{
Tingyu Wang, ${ }^{1}$ Jianqing Gong $\mathbb{D}^{,},{ }^{2}$ Bo Chen, ${ }^{1}$ Xiao Gong, ${ }^{1}$ Wanli Guo, ${ }^{2}$ Yang Zhang, \\ and Falei $\mathrm{Li}^{2}$ \\ ${ }^{1}$ Hunan Provincial Expressway Group Limited Company, Changsha, Hunan 410000, China \\ ${ }^{2}$ College of Civil Engineering, Hunan University, Changsha, Hunan 410082, China
}

Correspondence should be addressed to Jianqing Gong; gongjianqing@hnu.edu.cn

Received 16 April 2021; Accepted 14 May 2021; Published 26 May 2021

Academic Editor: Kim Hung Mo

Copyright ( $) 2021$ Tingyu Wang et al. This is an open access article distributed under the Creative Commons Attribution License, which permits unrestricted use, distribution, and reproduction in any medium, provided the original work is properly cited.

\begin{abstract}
Early strength generation is essential for the successful application and usage of Ultrahigh-Performance Concrete (UHPC) in reinforcing concrete structures. The work contained in this paper focused on evaluating the effects of lithium carbonate $\left(\mathrm{Li}_{2} \mathrm{CO}_{3}\right.$, denoted as LC) and nano-calcium carbonate (NC) on the early mechanical properties and autogenous shrinkage of UHPC under normal temperature curing conditions. In the study, scanning electron microscope (SEM) was utilized to investigate and quantify the morphology of the early hydration products. The corresponding results indicated that the 1-day comprehensive strength of the UHPC increased significantly with the addition of Li2CO3 and NC. Likewise, the addition of NC mitigated the loss of the 28-day compressive strength. For the materials evaluated, the 1-day compressive and flexural strengths reached peak values of 72.1 and 13.9 $\mathrm{MPa}$, respectively, for optimum dosages of $0.075 \% \sim 0.1 \% \mathrm{Li}_{2} \mathrm{CO}_{3}$ and $3 \% \sim 4 \% \mathrm{NC}$, respectively. The results also indicated that the combined LC-NC dosage had profound effects on the early autogenous shrinkage of UHPC, which could, however, be minimized by adjusting the $\mathrm{Li}_{2} \mathrm{CO}_{3}$ and $\mathrm{NC}$ dosages. That is, the combined dosage of the two early strength enhancers shortens the hydration induction period of cement whilst concurrently accelerating the hydration rate of the cement. The early strength agent increases the number of crystals in the hydration product and the crystal grain size becomes larger. These make the microstructure of the slurry more compact after hardening and therefore improve the overall performance of UHPC.
\end{abstract}

\section{Introduction}

Ultrahigh-Performance Concrete (UHPC) is a type of concrete with superior performance compared to ordinary concrete and high-performance concrete $[1,2]$. It has ultrahigh strength, toughness $[3,4]$, and excellent durability. The water-binder ratio is typically less than 0.25 [5]. The compressive strength of UHPC is usually more than $120 \mathrm{MPa}[6]$.

UHPC is widely used due to its excellent mechanical properties, durability, and overall performance. For instance, it can greatly reduce the weight of bridges and improve durability in bridge engineering $[7,8]$. It can also be used in restoration projects, such as repairing bridge deck defects
$[9,10]$, repairing bridge piers $[11,12]$, repairing anticollision layers [13], dams [14], and repairing tunnels $[15,16]$. Nonetheless, whilst the early strength develops slowly under normal temperature curing conditions, UHPC needs a hightemperature curing condition to obtain ultrahigh performance and high early strength. This does not only increase the construction challenges and cost but also hinder the wider application of UHPC to a certain extent, especially for engineering applications with high requirements for early strength, such as road and bridge repairs. In this study, lithium carbonate $\left(\mathrm{Li}_{2} \mathrm{CO}_{3}\right.$, simply denoted as $\mathrm{LC}$ in this paper) and nano-calcium carbonate (NC) were used as early strength enhancers to generate the high early strength of UHPC under normal temperature curing conditions. 
$\mathrm{Li}_{2} \mathrm{CO}_{3}$ is a colorless monoclinic crystal or white powder, which is a type of an inorganic compound. It has been widely used in the battery industry as well as a coagulant in cement admixture. $\mathrm{Li}_{2} \mathrm{CO}_{3}$ can improve the early strength of concrete. In general, the early strength enhancement derived from $\mathrm{Li}_{2} \mathrm{CO}_{3}$ is more significant than $\mathrm{NC}$; that is, there is more early strength gain with $\mathrm{Li}_{2} \mathrm{CO}_{3}$ usage than $\mathrm{NC}$. The incorporation of an appropriate amount of a setting accelerator in concrete can significantly shorten the setting time of concrete. With these accelerators, the concrete can reach the initial setting (or curing) within $5 \mathrm{~min}$ and the final setting within $10 \mathrm{~min}$. A certain degree of strength can be produced within one hour, and the strength can be increased to about twice the value after 1 day [17].

LC nanometer is a nanometer-sized type of an ultrafine material. Many scholars have explored the application and usage of these nanomaterials in UHPC. During UHPC production, nanomaterials can accelerate the hydration of cement, densify the microstructure, improve the strength, and improve the overall durability of UHPC. Therefore, nanomaterials can potentially be used as a new type of early strength enhancer. In their study, Sharma et al. found that nano- $\mathrm{SiO}_{2}$ (NS) particles can accelerate the early hydration rate of cement and promote the formation of single-sulfur type hydrated calcium sulphoaluminate phase in the hydration products [18]. Compared to NS, NC needs a greater amount of mixing to achieve the same effects. Huang et al. found that NC promoted the compressive strength of UHPC more significantly at an optimal mixing amount of 3\%-4\% [19]. The crystal core effects of NC were found to be the main reason for the increase in the concrete strength [20-22].

In this study, new nanoinorganic early strength enhancers, namely, $\mathrm{NC}$ and $\mathrm{Li}_{2} \mathrm{CO}_{3}$, were selected for laboratory experimentation to enhance the mechanical properties and shrinkage-resistance performance of UHPC. Under warm curing conditions, the variation in the mechanical properties of UHPC at the early stages (1-28 days) and its influence on UHPC autogenous shrinkage were studied using both single and combined dosage of the two early strength enhancers, namely, NC and LC. With the aid of the scanning electron microscope (SEM), the microstructure of the hydration products and the hardened slurry was observed and analyzed to quantify the hydration and strength mechanisms.

\section{Laboratory Experimentation}

The materials used in the study including the mix designs and sample preparation are presented and discussed in this section. The laboratory tests including strength, shrinkage, and morphological evaluation are also discussed in this section.

2.1. Materials Used. The cement used in this study was the P.O. 52.5 ordinary Portland cement. Its main chemical components are listed in Table 1. Grade I fly ash was used and its main chemical components are listed in Table 2. The slag powder used was S95-grade slag powder with a specific
TABle 1: P.O. 52.5 ordinary Portland cement chemical composition.

\begin{tabular}{lcccccc}
\hline $\begin{array}{l}\text { Chemical } \\
\text { composition }\end{array}$ & $\mathrm{Fe}_{2} \mathrm{O}_{3} \%$ & $\mathrm{Al}_{2} \mathrm{O}_{3} \%$ & $\mathrm{SO}_{3} \%$ & $\mathrm{CaO} \%$ & $\mathrm{SiO}_{2} \%$ & $\mathrm{MgO} \%$ \\
\hline Content & 4.51 & 5.76 & 2.02 & 64.5 & 0.23 & 1.4 \\
\hline
\end{tabular}

surface area of $422 \mathrm{~m}^{2} / \mathrm{kg}$. Its main components and technical indicators are shown in Table 3 and 4, respectively.

The particle size of quartz sand was $0.45 \sim 0.9 \mathrm{~mm} \mathrm{(20 \sim 40}$ mesh) and the mass fraction of $\mathrm{SiO}_{2}$ was more than $99 \%$. The silica fume was gray-white, with an average particle size of $89 \mathrm{~nm}$ and a specific surface area of $1.85 \times 104 \mathrm{~m}^{2} / \mathrm{kg}$. The water-reducing agent was sourced from a Construction Material Limited Company in Suzhou (China), with a waterreducing rate of more than $30 \% . \mathrm{Li}_{2} \mathrm{CO}_{3}$ (LC) was a white powder with a density of $2.11 \mathrm{~g} / \mathrm{cm}^{3}$ and a purity of over 99.5\%. The average particle size of NC was $60 \mathrm{~nm}$ whilst the mass fraction of $\mathrm{CaCO}_{3}$ was more than $99 \%$.

2.2. UHPC Mix Design. The water-binder (W/B) ratio for the mix design was 0.18 in this study. According to the preexperiment results, the content of silica fume, fly ash, and mineral powder was $20 \%, 5 \%$, and $5 \%$ of the cement quality, respectively. The sand-binder ratio was 1.1 and the water-reducing agent content was $1.0 \%$. The specific mix design is shown in Table 5.

2.3. Specimen Preparation and Curing Conditions. The materials required for the test were weighed according to the mix designs in Table 4 and poured into the mortar mixer. The materials were dry mixed for 2 minutes and then stirred continuously. The weighed water was then added and stirred at a slow speed for 5 minutes. After stirring was complete, the materials were stirred quickly for another 5 minutes. The mixed UHPC was first tested for fluidity and thereafter molded for strength, shrinkage, and microstructure testing. After placing the UHPC mix in the steel mold, it was then placed in an indoor temperature of $20 \pm 2^{\circ} \mathrm{C}$ and covered with plastic films for curing 28 days. At a minimum, three replicate specimens were prepared per material per mix design per test type per test condition.

2.4. Laboratory Testing. The methods for testing the compressive and flexural strengths are discussed in the subsequent. The UHPC compressive strength and flexural strength were tested according to the Test Method for Cement Mortar Strength GB/T17671-1999 [23]. For the flexural strength test, the standard size of the specimen is $40 \mathrm{~mm} \times 40 \mathrm{~mm} \times 160 \mathrm{~mm}$. First, the appearance and measurement of the specimen were checked. The specimen was then loaded continuously and uniformly at the speed of $0.08 \mathrm{MPa} / \mathrm{s}$ until failure, from which the failure load was captured and recorded. The compressive strength test was immediately carried out with the fractured cement mortar test block after the flexural test. The compressive fixture with a compression area of $40 \mathrm{~mm} \times 40 \mathrm{~mm}$ was used for which the load was applied uniformly at a rate of $2.4 \mathrm{kN} / \mathrm{s} \pm 0.2 \mathrm{kN} /$ 
TABLE 2: Chemical composition of fly ash.

\begin{tabular}{lccccccc}
\hline Chemical composition & $\mathrm{SiO}_{2}(\%)$ & $\mathrm{Al}_{2} \mathrm{O}_{3}(\%)$ & $\mathrm{Fe}_{2} \mathrm{O}_{3}(\%)$ & $\mathrm{CaO}(\%)$ & $\mathrm{SO}_{3}(\%)$ & $\mathrm{MgO}(\%)$ & $\mathrm{Loss}(\%)$ \\
\hline Content & 52.52 & 31.62 & 9.35 & 4.57 & 1.21 & 0.73 & 3.86 \\
\hline
\end{tabular}

TABle 3: Chemical composition of slag powder.

\begin{tabular}{lccccccc}
\hline Chemical composition & $\mathrm{SiO}_{2}(\%)$ & $\mathrm{Al}_{2} \mathrm{O}_{3}(\%)$ & $\mathrm{Fe}_{2} \mathrm{O}_{3}(\%)$ & $\mathrm{CaO}(\%)$ & $\mathrm{SO}_{3}(\%)$ & $\mathrm{MgO}(\%)$ & $\mathrm{Loss}(\%)$ \\
\hline Content & 78.64 & 5.01 & 0.28 & 7.00 & 1.21 & 3.4 & 4.41 \\
\hline
\end{tabular}

TABLe 4: Technical indicators of slag powder.

\begin{tabular}{lccccc}
\hline Variety specification & Density $\left(\mathrm{g} / \mathrm{cm}^{3}\right)$ & Specific surface area $\left(\mathrm{m}^{2} / \mathrm{kg}\right)$ & Liquidity ratio $(\%)$ & $7 \mathrm{~d}$ activity $(\%)$ & $28 \mathrm{~d}$ activity $(\%)$ \\
\hline S95 & 2.92 & 422 & 99 & 77 & 95 \\
\hline
\end{tabular}

TABLE 5: Basic mix design of high early strength UHPC.

\begin{tabular}{|c|c|c|c|c|c|c|c|c|c|}
\hline Group & $\mathrm{W} / \mathrm{B}$ & Cement & Silica fume & Fly ash & Mineral fines & Quartz sand & Water-reducing agent (\%) & $\mathrm{Li}_{2} \mathrm{CO}_{3}$ & $\mathrm{NC}$ \\
\hline$A 1 / B 1 / C 0$ & 0.18 & 1 & 0.20 & 0.05 & 0.05 & 1.1 & 1 & $0 \%$ & $0 \%$ \\
\hline$A 2$ & 0.18 & 1 & 0.20 & 0.05 & 0.05 & 1.1 & 1 & $0.075 \%$ & $0 \%$ \\
\hline$A 3$ & 0.18 & 1 & 0.20 & 0.05 & 0.05 & 1.1 & 1 & $0.1 \%$ & $0 \%$ \\
\hline$A 4$ & 0.18 & 1 & 0.20 & 0.05 & 0.05 & 1.1 & 1 & $0.125 \%$ & $0 \%$ \\
\hline$B 2$ & 0.18 & 1 & 0.20 & 0.05 & 0.05 & 1.1 & 1 & $0 \%$ & $2 \%$ \\
\hline$B 3$ & 0.18 & 1 & 0.20 & 0.05 & 0.05 & 1.1 & 1 & $0 \%$ & $3 \%$ \\
\hline$B 4$ & 0.18 & 1 & 0.20 & 0.05 & 0.05 & 1.1 & 1 & $0 \%$ & $4 \%$ \\
\hline B5 & 0.18 & 1 & 0.20 & 0.05 & 0.05 & 1.1 & 1 & $0 \%$ & $5 \%$ \\
\hline$C 1$ & 0.18 & 1 & 0.20 & 0.05 & 0.05 & 1.1 & 1 & $0.075 \%$ & $2 \%$ \\
\hline$C 2$ & 0.18 & 1 & 0.20 & 0.05 & 0.05 & 1.1 & 1 & $0.075 \%$ & $3 \%$ \\
\hline$C 3$ & 0.18 & 1 & 0.20 & 0.05 & 0.05 & 1.1 & 1 & $0.075 \%$ & $4 \%$ \\
\hline$C 4$ & 0.18 & 1 & 0.20 & 0.05 & 0.05 & 1.1 & 1 & $0.075 \%$ & $5 \%$ \\
\hline C5 & 0.18 & 1 & 0.20 & 0.05 & 0.05 & 1.1 & 1 & $0.1 \%$ & $2 \%$ \\
\hline C6 & 0.18 & 1 & 0.20 & 0.05 & 0.05 & 1.1 & 1 & $0.1 \%$ & $3 \%$ \\
\hline$C 7$ & 0.18 & 1 & 0.20 & 0.05 & 0.05 & 1.1 & 1 & $0.1 \%$ & $4 \%$ \\
\hline$C 8$ & 0.18 & 1 & 0.20 & 0.05 & 0.05 & 1.1 & 1 & $0.1 \%$ & $5 \%$ \\
\hline C9 & 0.18 & 1 & 0.20 & 0.05 & 0.05 & 1.1 & 1 & $0.125 \%$ & $2 \%$ \\
\hline$C 10$ & 0.18 & 1 & 0.20 & 0.05 & 0.05 & 1.1 & 1 & $0.125 \%$ & $3 \%$ \\
\hline$C 11$ & 0.18 & 1 & 0.20 & 0.05 & 0.05 & 1.1 & 1 & 0.125 & 4 \\
\hline$C 12$ & 0.18 & 1 & 0.20 & 0.05 & 0.05 & 1.1 & 1 & 0.125 & 5 \\
\hline
\end{tabular}

s until the specimen failed. The failure load was then measured and recorded.

The autogenous shrinkage properties were evaluated and tested using the SBT-AS early cement slurry, mortar, and concrete autogenous shrinkage strain tester. The method involved using a standard probe to sense/detect the distance between the probe and bellows clamp. Thereafter, the change in the UHPC volume was converted to the change in distance between the clamps and the probe. The inner/outer diameter of the bellows was $20 \mathrm{~mm}$ and $30 \mathrm{~mm}$, respectively, with a length of $340 \pm 5 \mathrm{~mm}$. Two test specimens were prepared for each test group, and the average value of the self-contraction value of the two specimens for each group was adopted. The testing range was $0-4 \mathrm{~mm}$, with a resolution of $0.5 \mathrm{~m}$ and an accuracy of $0.05 \%$.

For microstructure testing, a JSM-6490LV SEM model was used. That is, the SEM was used to observe the microstructure of cement-based materials when they were hydrated for 1 day, from which the strengthening and toughening mechanisms of the early strength enhancer were characterized and analyzed.

\section{Test Results, Analyses, and Synthesis}

The test results of the compressive and flexural strength evaluations are presented and discussed in this section. The results also include shrinkage evaluation and microstructure characterizing of the UHPC as a function of LC and NC, respectively.

3.1. Effects of the LC and NC Additives on the UHPC's Mechanical Properties. The UHPC mechanical properties that were measured and evaluated in this study include the compressive and flexural strengths. The results for these mechanical properties, namely, compressive and flexural strength, are presented, analyzed, and synthesized in the texts below. 
3.1.1. Compressive Test Results. Figure 1 shows the variational trend of the compressive strength as a function of curing age and LC-NC dosage. At one day (i.e., $1 \mathrm{~d}$ ) old, the UHPC compressive strength initially increased and then stabilized with an increase in the LC content. When the LC content reached $0.1 \%$, the $1 \mathrm{~d}$ compressive strength increased by about $44 \%$. At $3 \mathrm{~d}$, the UHPC compressive strength in Figure 1(a) initially increased and then stabilized with an increase in the LC content, which is almost similar to the $1 \mathrm{~d}$ response trend.

When the LC content was $0.1 \%$, the $3 \mathrm{~d}$ compressive strength in Figure 1(a) reached a maximum value of 87.4 MPa. At the curing age of 7 days (i.e., $7 \mathrm{~d}$ ), the compressive strength initially increased and then decreased with an increase in the LC content. Similarly, when the LC content reached $0.1 \%$, the $7 \mathrm{~d}$ compressive strength reached a maximum value of $105.3 \mathrm{MPa}$, with an increasing rate of $9 \%$. When the dosage of LC reached $0.125 \%$, the matrix strength of UHPC generally degenerated for all the curing ages evaluated. At the curing age of 28 days (i.e., $28 \mathrm{~d}$ ), LC had an adverse effect on the UHPC strength. With an increase in the LC content, the matrix strength generally exhibited a declining response trend.

As shown in Figure 1(b), the UHPC compressive strength at $1 \mathrm{~d}, 3 \mathrm{~d}, 7 \mathrm{~d}$, and $28 \mathrm{~d}$, respectively, was dependent on NC when NC was added. Just like LC, an increase in the $\mathrm{NC}$ amount yielded an initial increase in the compressive strength followed by a progressive decline, thereafter. In the case of NC, however, Figure 1(b) shows that the maximum compressive strength value occurred at $3 \%$ NC. The maximum compressive strength registered at $1 \mathrm{~d}$ was $62.4 \mathrm{MPa}$ whilst it was $95.8 \mathrm{MPa}$ at $3 \mathrm{~d}$. When the curing age was $7 \mathrm{~d}$ and $28 \mathrm{~d}$, the maximum compressive strengths recorded were 121.8 $\mathrm{MPa}$ and 33.7 $\mathrm{MPa}$, respectively. For NC dosages higher than 3\%, Figure 1(b) exhibits a downward response trend for the strength evolution.

As a result of NC single mixing, the early strength of UHPC was greatly improved. The $1 \mathrm{~d}$ compressive strength of UHPC for $0 \% \mathrm{NC}$ was $42.9 \mathrm{MPa}$. After adding 3\% NC, the compressive strength of UHPC reached $62.4 \mathrm{MPa}$ in one day, which increased by $45 \%$ compared with the control group. This is mainly because nano- $\mathrm{CaCO} 3$ can play the role of a microaggregate filler between cement and other mineral powder particles to improve the density of its accumulation and reduce the porosity. Compared with LC, the $28 \mathrm{~d}$ compressive strength of UHPC with NC was higher than that of the control group. This is mainly because nano$\mathrm{CaCO}_{3}$ can play the role of a microaggregate filler between cement and other mineral powder particles to improve the density of its accumulation and reduce the porosity.

Based on the single additive mixing experimentation results, the two enhancers were simultaneously combined into the UHPC matrix to study the combined effects of LC and NC on the UHPC mechanical properties. The content of LC was $0.075 \%, 0.1 \%$, and $0.125 \%$, respectively, whilst that of NC was $2 \%, 3 \%, 4 \%$, and $5 \%$, respectively. The experimental results for the combined LC-NC dosage are shown in Figure 2.

A comparison between Figures 1 and 2 shows that as $0.1 \%$ LC and $3 \%$ NC were added, the $1 \mathrm{~d}$ compressive strength reached its highest peak at $72.1 \mathrm{MPa}$ and thereafter declined progressively. Thus, whilst the single LC dosage significantly improved the early strength, the $28 \mathrm{~d}$ strength degenerated significantly and therefore was not conducive for long-term use. Single NC dosage also exhibited potential to improve the early strength, but unlike $\mathrm{LC}$, nano- $\mathrm{CaCO}_{3}$ greatly increased the $28 \mathrm{~d}$ strength of UHPC. When the two enhancers (i.e., LC and NC) were simultaneously mixed together, the $1 \mathrm{~d}$ compressive strength exceeded $70 \mathrm{MPa}$, and due to the LC-NC synergistic effects, a decay in the $28 \mathrm{~d}$ compressive strength that was noted in Figure 1 was somehow mitigated. That is, the LC-NC-combined additive increased the $1 \mathrm{~d}$ strength of UHPC by $68 \%$ with no adverse effects on the $28 \mathrm{~d}$ compressive strength of UHPC.

3.1.2. Flexural Test Results. The addition of $\mathrm{LC}$ and $\mathrm{CaCO}_{3}$ not only affects the UHPC compressive strength but also influences the flexural strength of UHPC. The test results of the UHPC flexural strength when LC and NC were added are shown in Figure 3 as a function of curing age. Figure 3(a) shows that when LC was added as a single dosage, the UHPC flexural strength initially increased and then stabilized after $1 \mathrm{~d}, 3 \mathrm{~d}$, and $7 \mathrm{~d}$ of aging with an increase in the LC dosage. When the LC dosage reached $0.1 \%$, the flexural strength evolution stabilized, with the $1 \mathrm{~d}$ flexural strength being about 12.8 MPa. However, the incorporation of LC has an adverse effect on the $28 \mathrm{~d}$ flexural strength of UHPC. With an increase in the LC content, the $28 \mathrm{~d}$ flexural strength of UHPC decreased progressively. Although LC can greatly improve the mechanical properties of UHPC in the early curing stages, an increase in dosage will degenerate the strength in the later stages of curing.

The effects of NC optimization on the UHPC flexural strength are shown in Figure 3(b). From the figure, it is evident that optimization of NC can significantly enhance the early flexural strength of UHPC. When the curing age was $1 \mathrm{~d}$, the UHPC strength varied as a function of $\mathrm{NC}$ dosage. The response trend shows an initial increase in the strength and then slightly degenerates to a maximum value of $12.9 \mathrm{MPa}$ at $3 \% \mathrm{NC}$. The flexural strengths of $3 \mathrm{~d}$ and $7 \mathrm{~d}$ aging reached their maximum values (namely, 20.3 MPa and $22.1 \mathrm{MPa}$, resp.) at $3 \% \mathrm{NC}$ content. Compared to the addition of LC in Figure 3(a), the UHPC flexural strength increased significantly with the addition of NC. The $28 \mathrm{~d}$ flexural strength of UHPC for $3 \% \mathrm{NC}$ was $19.2 \mathrm{MPa}$. At the age of 28 days (i.e., $28 \mathrm{~d}$ ), the flexural strength of UHPC for $3 \%$ NC greatly improved and reached a peak of $24.2 \mathrm{MPa}$, indicating an increase of $23 \%$.

In the optimization of $\mathrm{NC}$, when the dosage was $1 \% \sim 6 \%$, the increase in the UHPC flexural strength at $1 \mathrm{~d}$ aging was $11 \%, 21 \%, 28 \%, 25 \%, 21 \%$, and $17 \%$, respectively. From Figure 3(b), the increase in the flexural strength is most apparent at $3 \% \mathrm{NC}$, with the peak value also occurring at this dosage. However, the strength evolution slows down as the NC dosage increases above 3\% NC. At 3\% NC, the strength growth for $3 \mathrm{~d}$ UHPC flexural strengths was 23\%, 25\%, 32\%, $29 \%, 25 \%$, and $21 \%$, respectively. Overall, the strengthening effect of $3 \mathrm{~d}$ aging was more apparent, reaching a maximum 


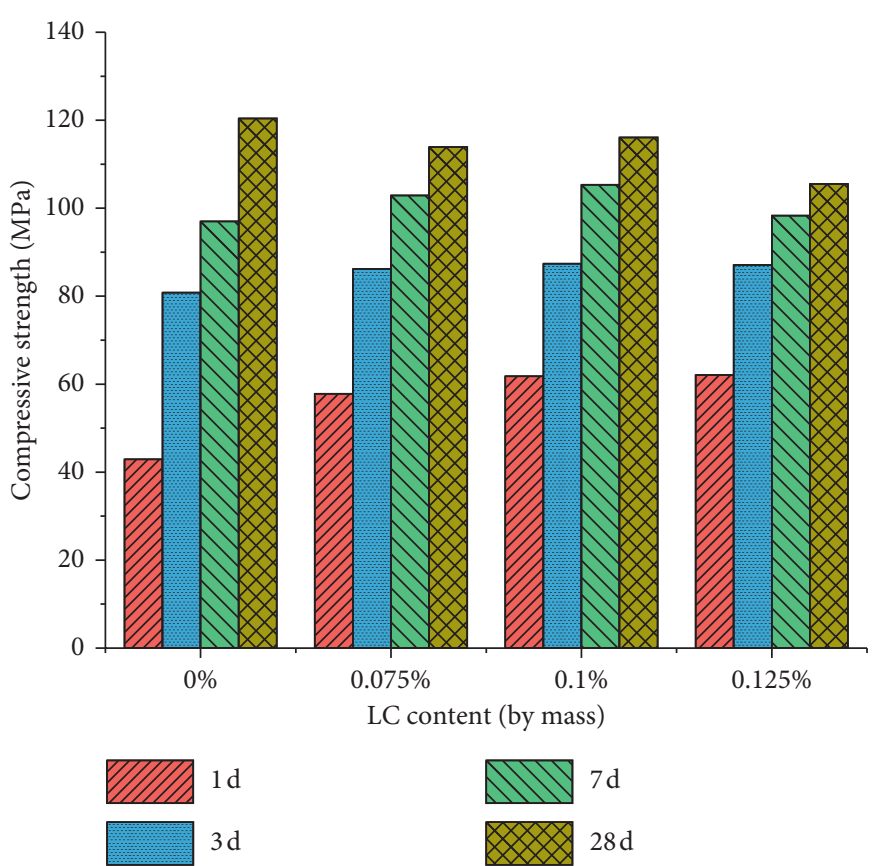

(a)

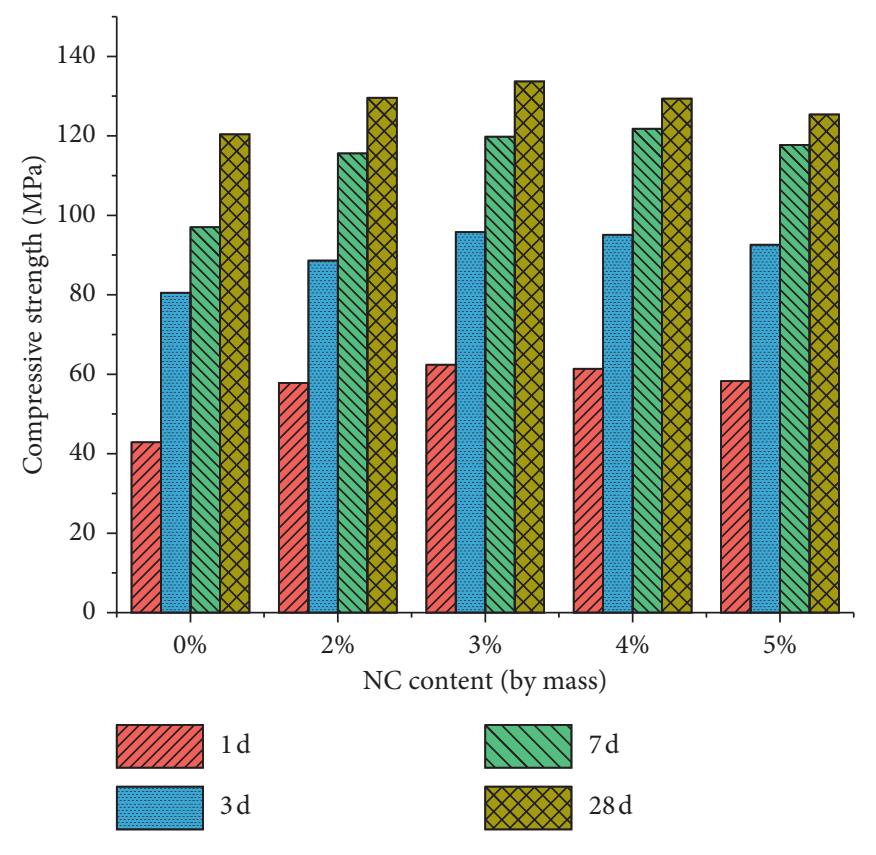

(b)

FIGURE 1: Effects of LC and NC single-type dosage on the UHPC comprehensive strength.

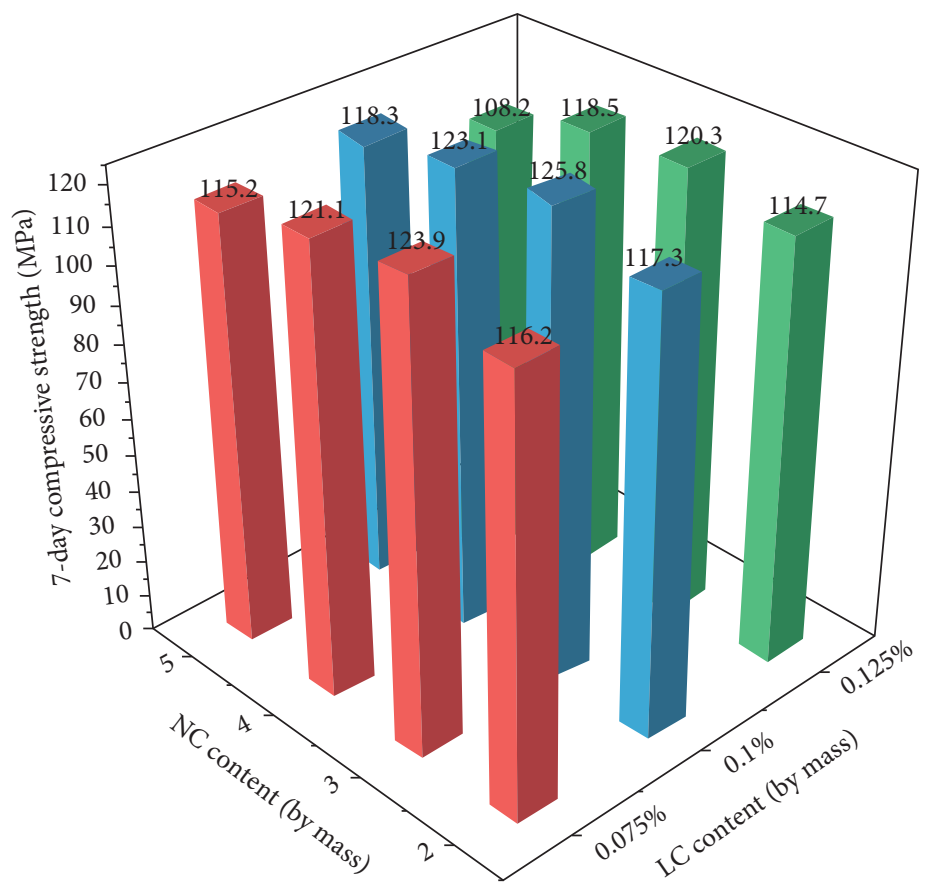

(a)

Figure 2: Continued. 


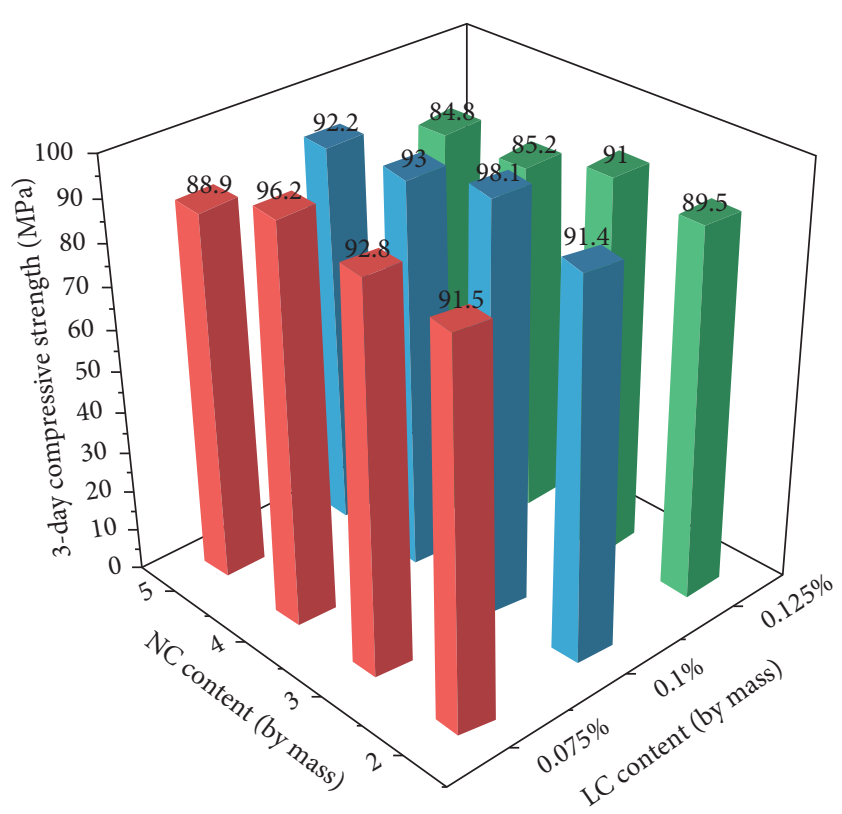

(b)

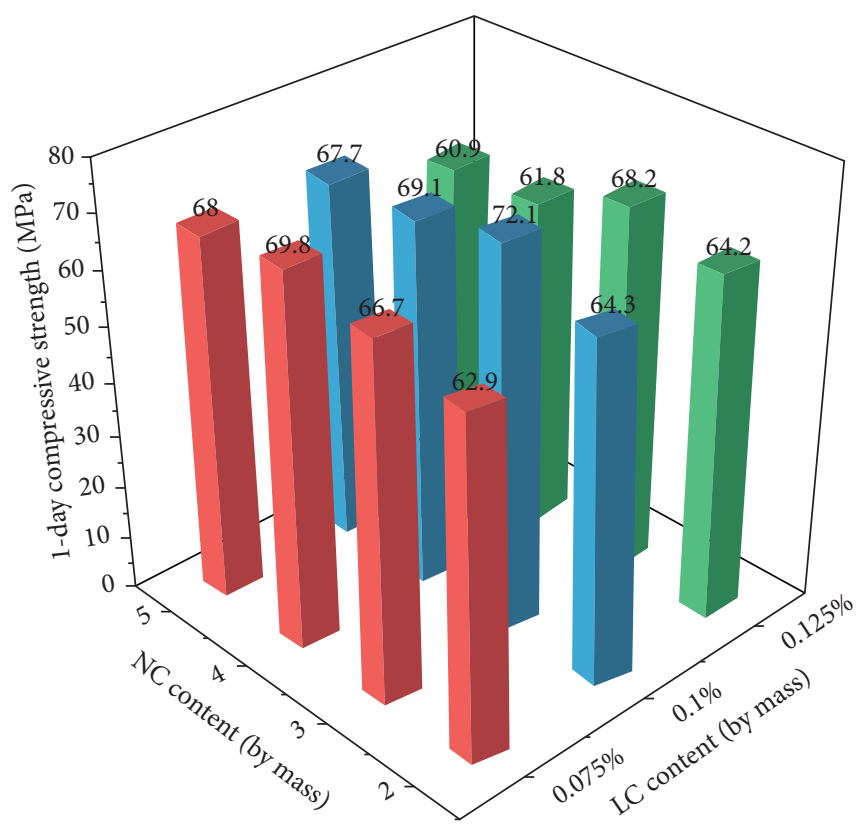

(c)

Figure 2: Continued. 


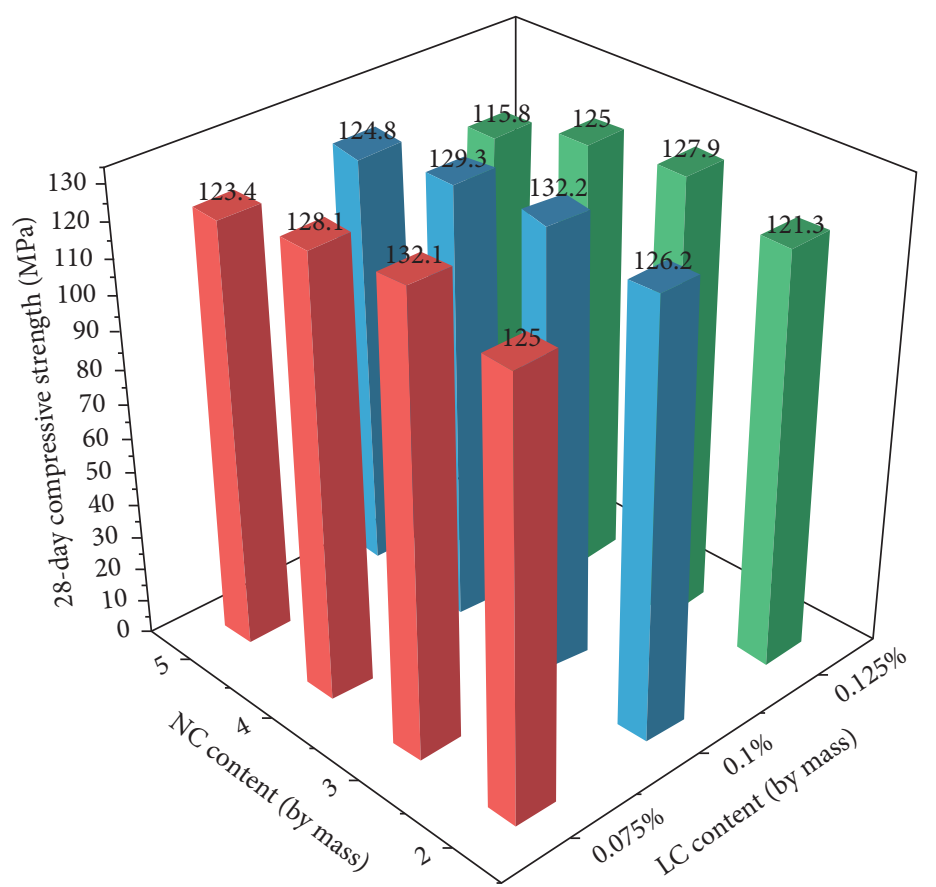

(d)

FIGURE 2: Effects of LC-NC combined additives on the UHPC compressive strength.

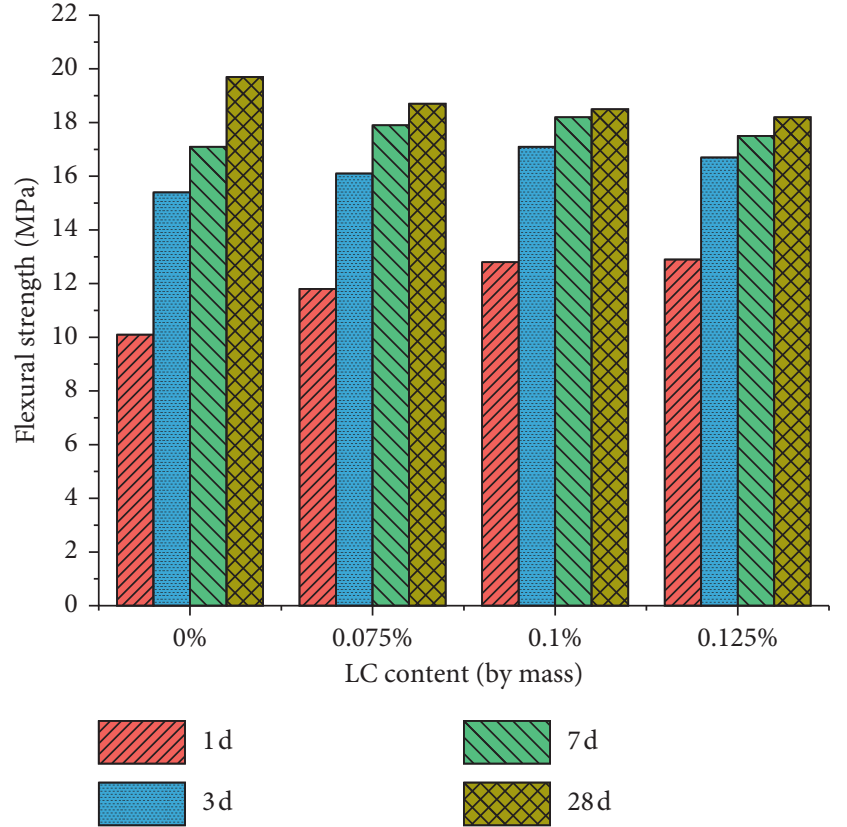

(a)

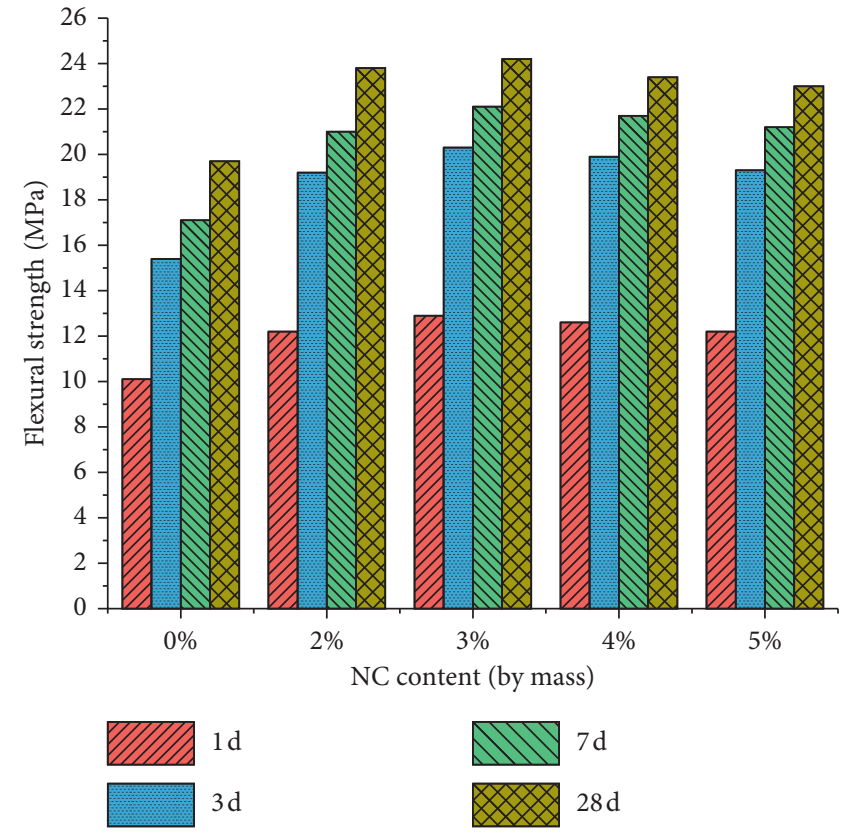

(b)

FIgURE 3: Effects of LC and NC single-type dosage on the UHPC flexural strength.

growth rate of $32 \%$ for $3 \%$ NC. For $7 \mathrm{~d}$, the corresponding growth rates were $20 \%, 23 \%, 29 \%, 27 \%, 24 \%$, and $18 \%$, respectively, with $29 \%$ being the highest increment. These increments are hardly different for $1 \mathrm{~d}$ and $3 \mathrm{~d}$ aging for $3 \%$ nano- $\mathrm{CaCO}_{3}$ dosage. From these results, it is evident that
NC has a significant enhancement effect on the early strength generation of UHPC and that the strength enhancement was most apparent for 3\% NC dosage. However, a continuous increase in the NC content will significantly reduce the UHPC fluidity and decrease the strength 
evolution. Therefore, $3 \%$ is recommended as the optimum NC dosage. Figure 4 shows the combined effects of LC-NC dosage on the UHPC flexural strength.

From Figure 4, it is apparent that the $1 \mathrm{~d}$ flexural strength was highest at $13.9 \mathrm{MPa}$ for $0.1 \% \mathrm{LC}$ and $3 \% \mathrm{NC}$, respectively. When comparing with Figure 3, it is evident that the single dosage of LC can significantly improve the early strength of UHPC but greatly degenerated the $28 \mathrm{~d}$ flexural strength. Similarly, single doped NC also significantly improved the early UHPC flexural strength. At $28 \mathrm{~d}$ aging, however, the UHPC flexural strength could potentially be increased by about $10 \% \sim 24 \%$. When the two LC-NC enhancers are mixed together, the UHPC flexural strength at $1 \mathrm{~d}$ and $28 \mathrm{~d}$ aging could potentially be increased by up to $38 \%$ and $24 \%$, respectively.

\subsection{Effects of the LC and NC Additives on UHPC's Autogenous} Shrinkage. Figure 5 shows the influence of LC on UHPC selfcontraction under different dosages, namely, $0.075 \%, 0.1 \%$, and $0.125 \%$, respectively. It can be seen from Figure 5 that the shrinkage of the group with added LC is larger than the specimens without LC. The experimental data show that the shrinkage rate of the specimens without LC was $1147 \mathrm{~mm}^{-1}$ and $1332 \mathrm{~mm}^{-1}$ for $0.075 \% \mathrm{LC}$, respectively, which is $16 \%$ higher than the reference group, that is, control specimens without LC. From the figure, the self-shrinking of UHPC with $0.1 \% \mathrm{LC}$ was found to be $1738 \mathrm{~mm}^{-1}$, which is about $52 \%$ higher than that of the control specimens (or reference group). For $0.125 \%$ LC, the shrinkage was $1917 \mathrm{~mm}$, an increase of about $67 \%$ over the control specimens, that is, the reference group. In comparison to specimens containing LC, the contraction growth rate (slope of the response curve) of the NC modified specimens at the early stage of curing was relatively small. This behavioral response trend may be caused by LC promoting the formation of some AFt crystals whilst ettringite has an expansive effect and partially compensates for the contraction effect. After the formation of the concrete matrix, the contraction tends to be stable.

The damage of the hydration protective film on the surface of the cement particles was accelerated due to $\mathrm{Li}^{+}$ having a small ionic radius and strong polarization effects. Additionally, the hydration induction period of cement was greatly shortened whilst the mineral component $\mathrm{C}$ was expanded. However, the continuous hydration of cement is considered the root cause of autogenous shrinkage. The hydration rate, degree of hydration degree, and the hydration water content of the cement minerals are some of the key factors that potentially affect autogenous shrinkage.

The effect of hydration products on the shrinkage of concrete is generally different depending on the hydration products. The hydration process of $\mathrm{C}_{3} \mathrm{~A}$ requires a large amount of water. It gives off a lot of heat. Therefore, the hydration reaction of $\mathrm{C}_{3} \mathrm{~A}$ has the greatest influence on the autogenous shrinkage of concrete. The incorporation of LC greatly promotes the hydration rate of cement due to the high content of sulfur in Portland cement.

Figure 6 shows the effects of nano- $\mathrm{CaCO}_{3}$ with different $\mathrm{NC}$ dosages on the autogenous shrinkage performance of
UHPC. In general, an excessive amount of mixing significantly impacts the UHPC fluidity, which could potentially make the slurry be very thick and difficult to be stirred/ blended. For ease of use and constructability considerations, three different NC dosages, namely, $2 \%, 3 \%$, and $4 \%$, respectively, were selected to evaluate the autogenous shrinkage of UHPC; see Figure 6.

From the test results in Figure 6, the following conclusions were derived. The mix ratio can potentially show an early UHPC microexpansion effect mainly because of the cement condition and other mineral admixtures after being fully mixed with water. Calcium silicate and the active mineral admixture in the cement composition react quickly with water, thus releasing a large amount of hydration heat, with a slight swelling effect at the beginning of the reaction.

In Figure 6, the B1 group did not contain NC whilst B2, $\mathrm{B} 3$, and $\mathrm{B} 4$ had $2 \%, 3 \%$, and $4 \%$ nano- $\mathrm{CaCO}_{3}$, respectively. The addition of NC shows distinctive initial microexpansion effects in the cement matrix. By observing the trends and changes in the response curve, it can be seen that the shrinkage of UHPC increased significantly before $10 \mathrm{~h}$, that is, 10 hours. The slope of the curve is very steep, indicating that, during this time, lots of hydration reactions took place within the UHPC, which ultimately generates a large number of hydration products whilst consuming a large amount of water. This in turn results in the continuous decrease of the overall volume with a large contraction. It can be seen from Figure 6 that, during the early stages of NC being added, the slope of the self-contraction response curve of $\mathrm{CaCO}_{3}$ was larger than that of the control group without NC. This indicates that the incorporation of nano- $\mathrm{CaCO}_{3}$ can accelerate the hydration reaction rate of cementitious materials and promote the secondary hydration reaction of cement and to some extent other active mineral components as well. This not only significantly improves the early strength evolution but also produces large shrinkage.

As the hydration reaction progresses, the internal "selfdrying" effect becomes apparent because the water glue of UHPC is relatively low. Additionally, the hydration reaction consumes a large amount of free water, particularly nano$\mathrm{CaCO}_{3}$. At about 72 hours, the shrinkage of the control group without the enhancers (i.e., $B 1$ ) was smaller than that of the group with the enhancers. The experimental data showed that no nano- $\mathrm{CaCO}_{3}$ was added to $\mathrm{B} 1$. The shrinkage of the specimens with $2 \% \mathrm{NC}$ was $1147 \mathrm{~mm}^{-1}$, which was self-shrinking to $1858 \mathrm{~mm}^{-1}$ and translating to about $62 \%$ higher than the reference or control group, that is, $B 1$. The self-shrinking rate of $3 \% \mathrm{NC}$ was $1938 \mathrm{~m} \cdot \mathrm{m}^{-1}$ and represented about $69 \%$ higher than the reference group. The autogenous shrinkage of $4 \% \mathrm{NC}$ is $1779 \mathrm{~mm}^{-1}$, an increase of $55 \%$ over the reference or control group, namely, $B 1$.

From the above analysis, it can be seen that the incorporation of NC greatly improved the self-contraction of UHPC. When the cement is hydrated, a large amount of water is consumed, causing the pored liquid level to drop. This forms the minuscule surface and ultimately results in the so-called self-drying effect. As a result, the internal volume of the whole cement slurry decreases. The early strength of concrete develops rapidly and causes the early 

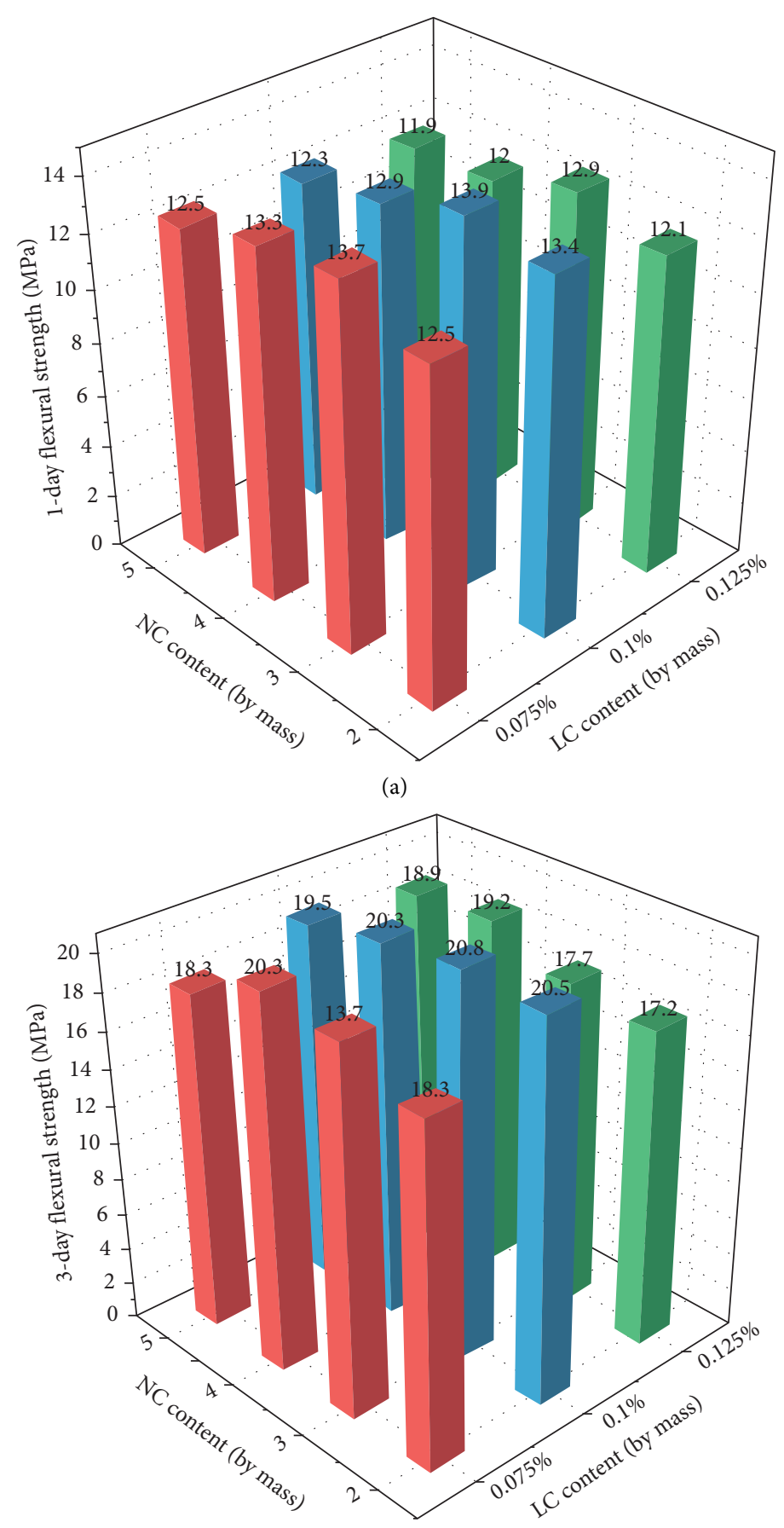

(b)

Figure 4: Continued. 


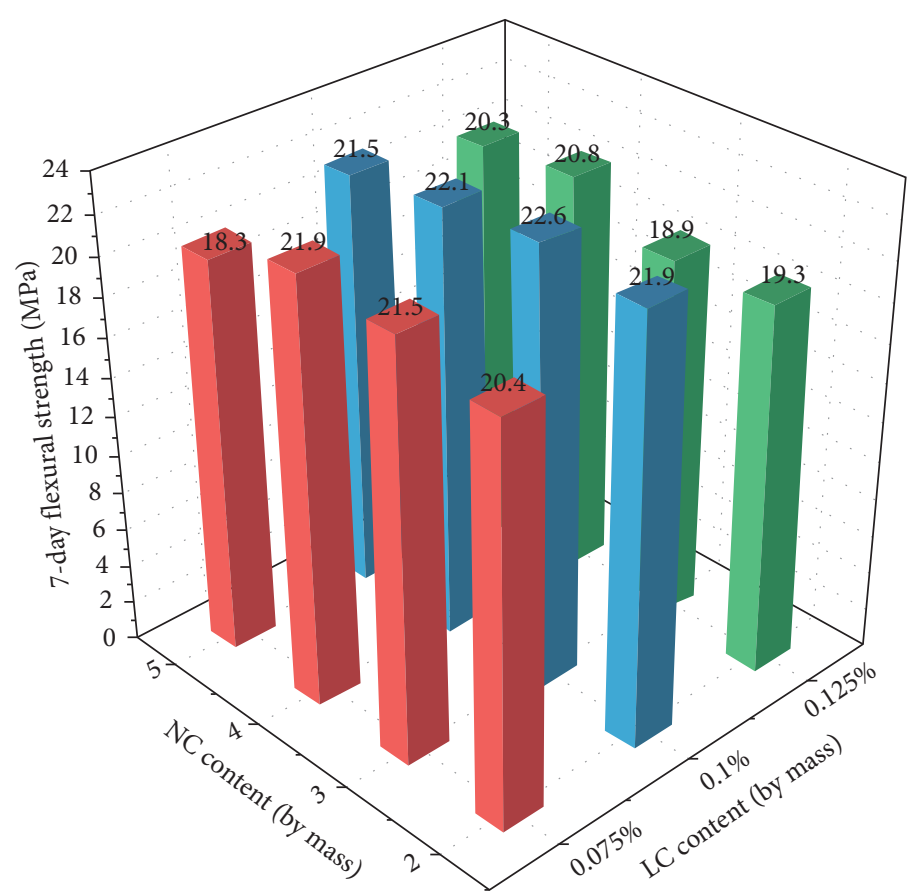

(c)

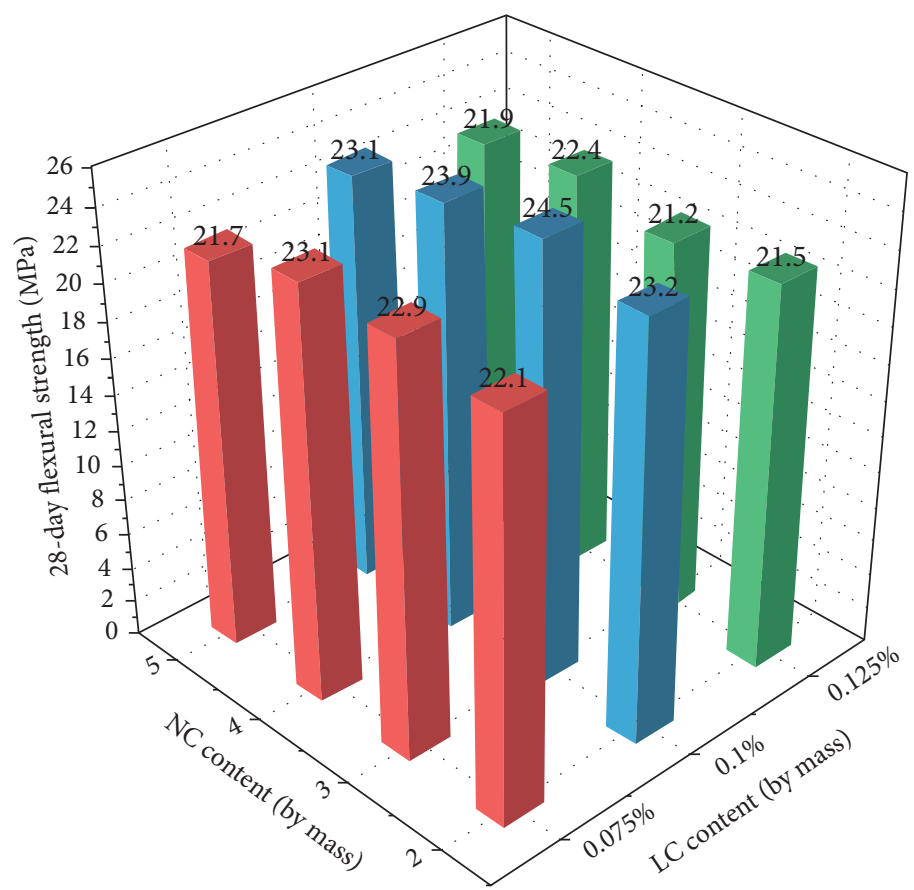

(d)

FIgURE 4: UHPC flexural strength with LC-NC combined dosage.

formation of the concrete skeleton due to the early strength effects of NC. Therefore, as time goes by, the formation of hydration products has little impact on the macroscopic volume change of concrete. As can be seen from Figure 6, the curve gradually flattens out with no significant increase. In addition, the shrinkage was relatively smaller for the $4 \%$ dosage (i.e., B4), which may be due to the filling of many nanometer particles partially compensating for some shrinkage. On the other hand, with an increase in the NC dosage, the water absorption would correspondingly increase, thus slowing down the hydration reaction rate to some extent.

The design mix groups were $C 5, C 6$, and $C 7$, respectively. The LC content was maintained constant at $0.1 \%$ whilst that 


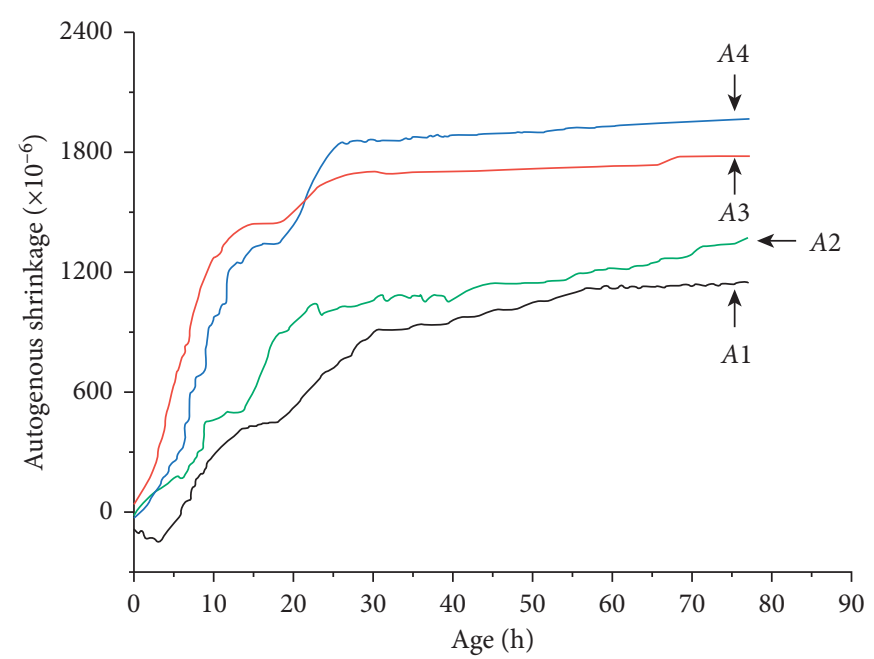

FIGURE 5: Effects of LC on the autogenous shrinkage of UHPC $(A 1=0 \% \mathrm{LC} ; A 2=0.075 \% \mathrm{LC} ; A 3=0.1 \% \mathrm{LC} ; A 4=0.125 \% \mathrm{LC}$; h= hour $)$.

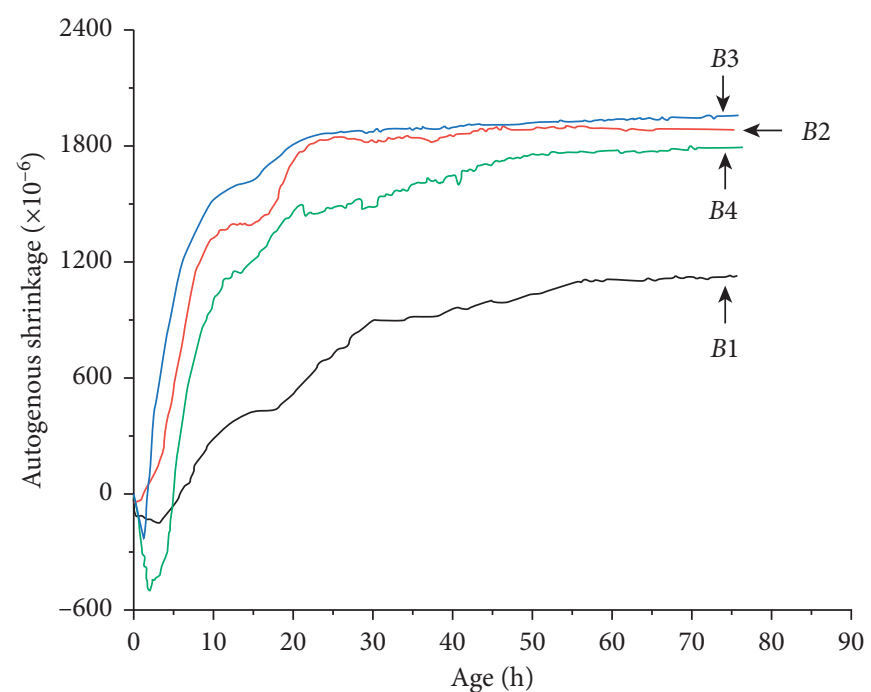

FIGURE 6: Effects of NC on the autogenous shrinkage of UHPC $(B 1=0 \% \mathrm{NC} ; B 2=2 \% \mathrm{NC} ; B 3=3 \% \mathrm{NC} ; B 4=4 \% \mathrm{NC}$; h= hour $)$.

of NC was selected as $2 \%, 3 \%$, and $4 \%$, respectively. The results of the combined LC-NC dosage on the early selfcontraction of UHPC are shown in Figure 7.

As shown in Figure 7, under the action of a combined LC-NC dosage, the autogenous shrinkage of UHPC at $72 \mathrm{~h}$ increased significantly in comparison to the single-type dosage. The experimental data indicated that when $0.1 \%$ LC and $2 \%$ NC were added, the autogenous shrinkage of UHPC at $72 \mathrm{~h}$ increased significantly. The shrinkage value at $72 \mathrm{~h}$ was $2291 \mathrm{~mm}^{-1}$, which was $100 \%$ higher than the shrinkage value of the reference group, that is, $C 1$. For $0.1 \% \mathrm{LC}$ and $3 \% \mathrm{NC}$, the shrinkage value at $72 \mathrm{~h}$ was $3100 \mathrm{~mm}^{-1}$, which was $170 \%$ higher than the contraction value of the reference group, namely, $C 1$. At $0.1 \%$ LC and $4 \%$ NC dosages, the shrinkage value at $72 \mathrm{~h}$ was $2897 \mathrm{~mm}^{-1}$, representing $153 \%$ higher than the contraction value of the reference group, namely, $C 1$. Form these results, it is obvious that the combined incorporation of LC and NC significantly improved the early strength of
UHPC and accelerated the hydration rate of UHPC in the early curing stages, thus greatly increasing the early autogenous shrinkage of UHPC. Therefore, the method to reduce the autogenous shrinkage of UHPC under the normal temperature curing conditions remains a problem warranting future exploration and research investigations.

\subsection{Effects of the LC and NC Additives on the Microstructure of} UHPC. In this laboratory experimentation, the microstructure and morphology of UHPC with and without the LC-NC additives were observed under vacuum conditions using the SEM. For SEM characterization, the $A 0$ (without additives) and C6 (fastest early strength growth) specimens at $1 \mathrm{~d}$ aging were selected for microstructural analysis. Figure 8 shows the $A 0$ (without LC-NC additives) micromorphological results for $1 \mathrm{~d}$ specimens cured with film mulching at room temperature. 


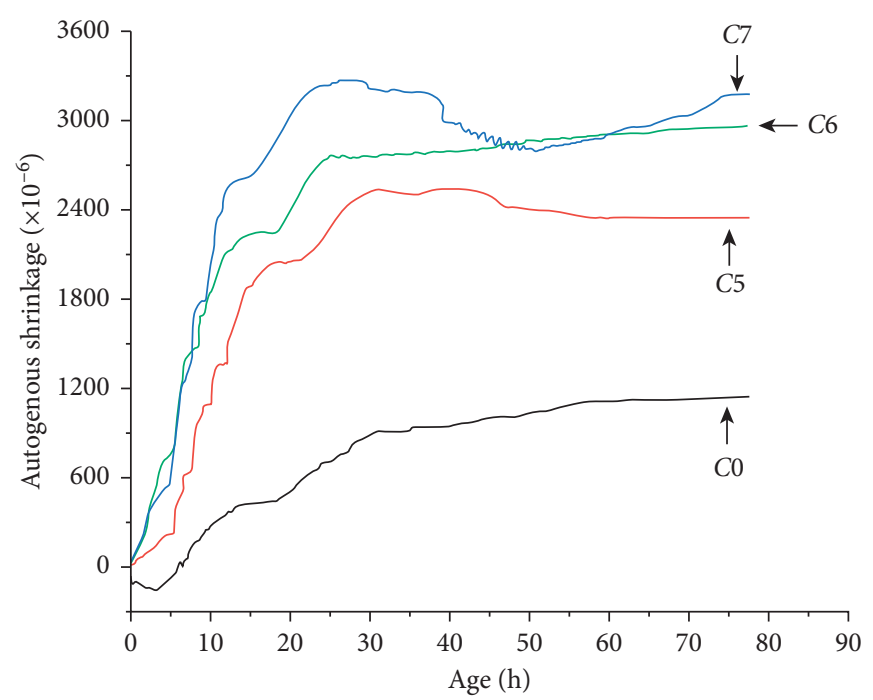

FIGURE 7: Effects of LC and NC combined additives on the autogenous shrinkage of UHPC (C0 $=0 \%$ LC and $0 \%$ NC; C5 $=0.1 \%$ LC and $2 \%$ NC; $C 6=0.1 \%$ LC and $3 \% \mathrm{NC} ; \mathrm{C7}=0.1 \% \mathrm{LC}$ and $4 \% \mathrm{NC}$; $\mathrm{h}=$ hour).

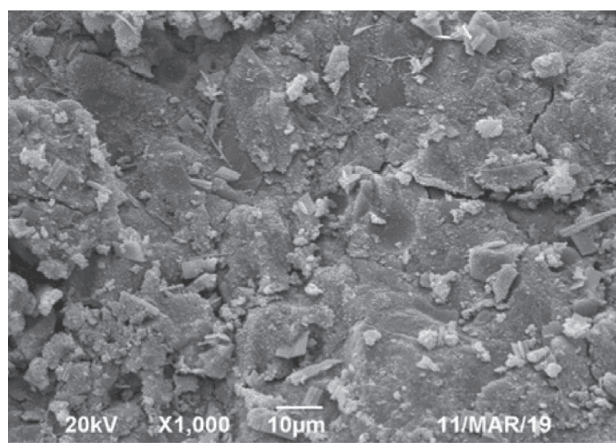

(a)

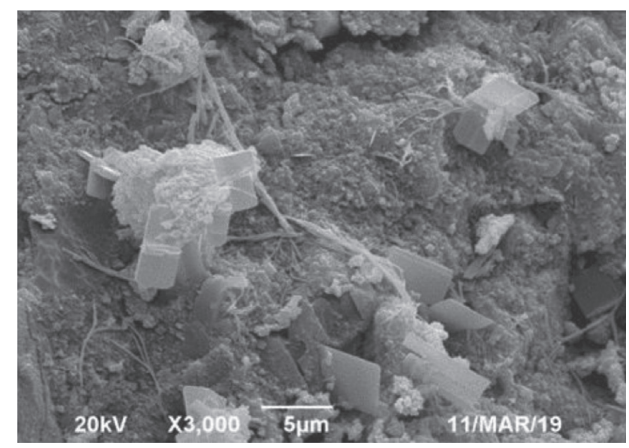

(b)

FIgURE 8: Microstructure of UHPC without LC-NC additives.

It can be seen from Figure 8 that, due to the relatively low degree of hydration in the early stages of curing, some fine pores appear in the concrete matrix. Under normal temperature curing conditions, part of the hydration reaction occurs within the UHPC matrix. However, as can be seen from Figure 8, there are still numerous unhydrated particles within the UHPC matrix, causing its early strength to be relatively low. From Figure 8 (b), although it is only $1 \mathrm{~d}$, the internal hydration products are unevenly distributed. From the figure, it can also be seen that the quantities of $\mathrm{Ca}(\mathrm{OH})_{2}$ crystals and $\mathrm{C}-\mathrm{S}-\mathrm{H}$ gel are relatively small.

Figure 9 shows the addition of $\mathrm{LC}$ and $\mathrm{NC}_{3}$ on the micromorphology of the $1 \mathrm{~d}$ specimen cured with film mulching at room temperature. As can be seen in Figure 9, the combined incorporation of LC and NC sped up the rate of cement hydration. The hydration products of the reference group $(A 0)$ are more apparent, with the crystals significantly increasing in terms of both numerical counts and grain sizewise. Also, a large number of AFt crystals and $\mathrm{C}-\mathrm{S}-\mathrm{H}$ became close together and resulted in a more compact structure. This greatly enhances the mechanical properties of UHPC as $\mathrm{Li}+$ with a smaller ionic radius induces a strong polarization effect and accelerates the hydration of cement particles to generate a surface protective film. This in turn greatly shortened the cement hydration induction period and expanded the mineral composition of $\mathrm{C}_{3} \mathrm{~S} / \mathrm{C}_{2}$ as well as the area of contact between sulfur and water-ultimately raising the $\mathrm{C}_{3} \mathrm{~S}_{2} \mathrm{C}_{2}$ content and the hydration rate of $\mathrm{S}$. On the other hand, due to the $\mathrm{CaCO}_{3}$ nucleation effects when $S$ starts to hydrate, $\mathrm{Ca}^{2+}$, with a strong migration ability, is released. Based on the adsorption theory and coion effect, when $\mathrm{Ca}^{2+}$ is diffused in $\mathrm{NC}_{3}$, the particle surface will be adsorbed and create $\mathrm{C}_{3} \mathrm{Ca}$ around the $S$ particles, thus reducing the concentration and ultimately promoting the $C$ generation and to some extent the hydration of $S$.

By comparing Figures 8 and 9, it can be observed that when LC-NC is added, the structure of UHPC is more compact and is mainly attributed to nano- $\mathrm{CaCO}_{3}$. The microaggregate effect of $\mathrm{NC}$ is that the average particle size of UHPC is about $60 \mathrm{~nm}$, which can be filled in the particle gap between cement, fly ash, ore powder, and silica fume. 


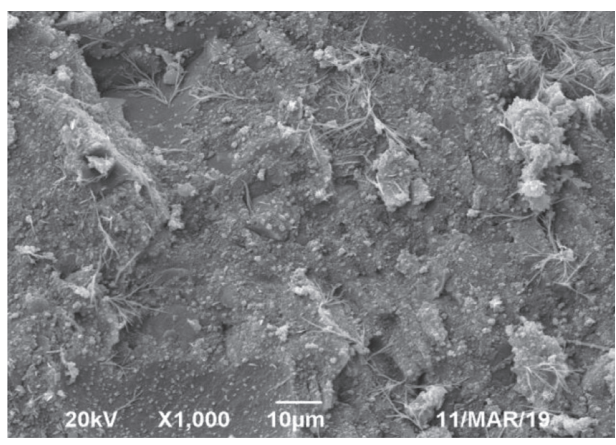

(a)

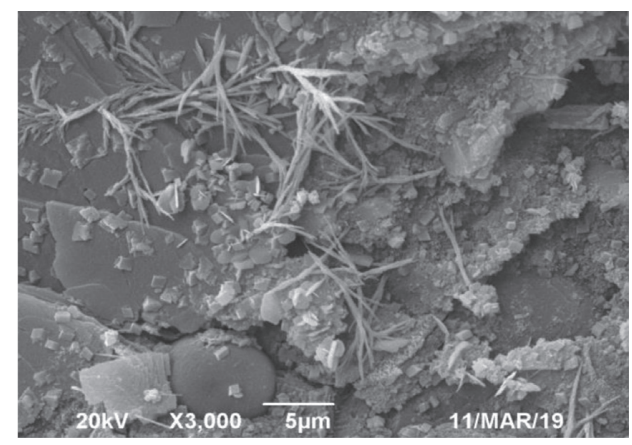

(b)

Figure 9: Microstructure of UHPC with LC-NC additives 2.

This filling effect results in compacting the structure of UHPC and reducing its internal defects, thus improving the early mechanical properties of UHPC. On the other hand, some NC gets embedded in the cement slurry, due to the "pinning" effect of NC. The existence of NC restricts the development of cracks, thus playing a role in improving the overall toughness of the UHPC matrix.

\subsection{Effects of LC-NC Additives on the Strength Enhancement Mechanism of UHPC. As can be seen from the previous test results, LC and NC were cured at room temperature. In general, the early mechanical properties of UHPC greatly improved with the addition of LC and NC, respectively. As discussed below, the mechanism of action and strength enhancement include microaggregate effects and synergistic hydration.}

3.4.1. Microaggregate Effects. The particle size of nanomaterials is on the scale of nanometer $(1-100 \mathrm{~nm})$. Its characteristic properties include the following: (1) the particle size is smaller than the usual powder but larger than the atomic cluster, and (2) the particle size is small but with a large specific surface area. For NC, the average particle size of $\mathrm{CaCO}_{3}$ is about $60 \mathrm{~nm}_{3}$, and as a nanoscale material, it has a small size and surface effects. After it is added to the UHPC colloidal particles, the pores are initially filled to improve the pore structure with an increase in the accumulation density of the powder [24, 25]. In traditional UHPC, silica dust is usually the smallest particle and can improve the particle gradation of UHPC. For nano- $\mathrm{CaCO}_{3}$, the addition of wollastonite further fills the pores inside and between the silica ash and other particles, which further increases the density of the cementing system $[26,27]$. Nano- $\mathrm{CaCO}_{3}$ can also produce a pinning effect on the interface of the cement particles, which not only prevents further expansion of the internal crack of cement particles to some extent but also improves the early compressive strength evolution of UHPC.

3.4.2. Synergistic Hydration. Portland cement clinker contains a large amount of $C$. The content of the $S$ mineral can reach up to $60 \%$ and its hydration reaction rate is high. The nature of hardened cement slurry is largely determined by $C$ and the hydration of $S$. Firstly, lithium ions are characterized by their small radius and strong polarization. Comparatively speaking, lithium ions are more likely to pass through and/or enter the hydration film, which accelerates the destruction of the hydration protection film on the surface of the cement particles [28] and also expands the mineral component $\mathrm{C}_{3} \mathrm{~S}$ / $\mathrm{C}_{2}$. Additionally, the contact area between $S$ and water promotes the flow of calcium ions into the film to the outside of the film and breaks through the hydration film due to the coion effects. This promotes cement hydration, shortens the cement induction period, and accelerates the hydration reaction to improve the $C$ in the cement. The hydration ability of $S$ under normal temperature curing conditions generates more hydration products at the early stages, thus improving the early mechanical properties of UHPC.

3.5. Effects of the LC-NC Additives on the Shrinkage Mechanism of UHPC. In the hydration process of concrete, a large amount of water will be consumed, resulting in a decrease of the wool stoma liquid level that is often called the "selfdrying" effect [29], and causes the occurrence of menisci in the wool stoma of concrete. The strong hydration promotes the rapid advance of the capillary lemnisci in concrete, with the hardened cement particles being subjected to negative pressure. As the hydration reaction takes place, the humidity inside the concrete is reduced because the reaction process consumes a large amount of moisture, which ultimately reduces the critical radius $r$ whilst the capillary suction $\Delta \mathrm{P}$ $(\mathrm{Pv}-\mathrm{Pc})$ increases. Negative pressure acts on the tube wall around the capillary tube to produce compressive stress. When the relative humidity decreases to a lower level, the stress caused by the negative pressure of the capillary tube increases rapidly. This causes the cement particles to contract and induce self-contraction (shrinkage) of the whole concrete matrix.

The continuous hydration of cement is technically viewed as the root cause of autogenous shrinkage. Tazawa proposed an empirical formula to predict the autogenous shrinkage of cement slurry after its hydration for $1 \mathrm{~d}$ based on the experimental regression of the mineral composition of ordinary Portland cement as follows [30]: 


$$
\sum(\mathrm{t})=0.012 \mathrm{alpha}_{\mathrm{C} 3 \mathrm{~S}}(\mathrm{t}) \mathrm{PC} 3 \mathrm{~S} 0.070 \text { alpha. }_{\mathrm{C} 2 \mathrm{~S}}(\mathrm{t}) \mathrm{PC} 2 \mathrm{~S}+2.256 \text { alpha. }_{\mathrm{C} 3 \mathrm{~A}}(\mathrm{t}) \mathrm{PC} 3 \mathrm{~A}+0.085 \text { alpha. }{ }_{\mathrm{C} 4 \mathrm{AF}}(\mathrm{t}) \mathrm{PC} 4 \mathrm{AF}
$$

According to equation (1), the mineral composition of the cement clinker can affect the shrinkage of concrete. The fastest hydration rate is $\mathrm{C}_{3} \mathrm{~A}$ and has the greatest influence and its combined water content is also the highest. This is followed by $\mathrm{C}_{4} \mathrm{AF}$ and $\mathrm{C}_{3} \mathrm{~S}$ with $\mathrm{C}_{2} \mathrm{~S}$ having the least impact. Based on the previous test results, the addition of $\mathrm{LC}$ and $\mathrm{NC}$ accelerated the early hydration rate of UHPC, thereby greatly improving its early strength evolution. The greater the degree of hydration (i.e., the more the hydration products), the greater the capillary pressure, ultimately resulting in the UHPC undergoing self-contraction.

\section{Conclusions and Recommendations}

This study was conducted to evaluate the effects of $\mathrm{Li}_{2} \mathrm{CO}_{3}$, denoted as LC, and NC on the early mechanical properties and autogenous shrinkage of UHPC under normal temperature curing conditions. The materials used comprised of P.O. 52.5 ordinary Portland cement, grade I fly ash, and S95grade slag powder whilst the additives were LC and NC, respectively. In the study, SEM was utilized to investigate and quantify the morphology of the early hydration products of the UHPC. From the study results and findings, the following conclusions and recommendations were drawn:

(i) The results indicated that the $1 \mathrm{~d}$ comprehensive strength of UHPC increased significantly with the combined LC-NC dosage with NC effects being instrumental in mitigating the $28 \mathrm{~d}$ comprehensive strength loss. The $1 \mathrm{~d}$ comprehensive and flexural strengths reached peak values of $72.1 \mathrm{MPa}$ and 13.9 MPa, respectively. Compared with the reference specimens, the $1 \mathrm{~d}$ comprehensive and flexural strength of the modified UHPC had strength gains of about $68 \%$ and $38 \%$, respectively. Based on the study findings, the recommended optimum dosages are $0.075 \% \sim 0.1 \% \mathrm{LC}$ and $3 \% \sim 4 \% \mathrm{NC}$, respectively.

(ii) For single-type dosage, both LC and NC can potentially increase the early self-contraction of UHPC, with 3\% NC being the optimum additive content. With the LC-NC additives, the self-contraction ratio of UHPC was increased by $69 \%$ over the reference group. The autogenous shrinkage corresponding to $0.125 \% \mathrm{LC}$ was $67 \%$ higher than that of the reference group without any LC-NC additives.

(iii) Under the combined action of LC-NC dosage, the early self-contraction of UHPC greatly increased due partially to the "superposition" effects of the LC-NC additives. Compared with the reference group, the increase in UHPC self-contraction after the combined dosage of the LC-NC additives ranged from $100 \%$ to $170 \%$, which is significantly larger than the UHPC self-contraction when only one additive is used. (iv) Under the combined action of LC-NC dosage and for $1 \mathrm{~d}$ curing time, the following were observed: (1) the hydration rate of the cement was accelerated; (2) the hydration products were more apparent in the reference group; (3) the number of crystals was significantly increased and coalesced into larger grain sizes; and (4) a large number of AFt crystals became closely packed with $\mathrm{C}-\mathrm{S}-\mathrm{H}$. This resulted in the matrix structure being very compact and thus greatly improved the early mechanical properties of UHPC.

(v) The experimental test results showed that LC-NC can be used as early strength enhancers to produce high early strength UHPC under normal temperature curing conditions, with no adverse effects on the $28 \mathrm{~d}$ strength of UHPC. This ultimately substantiates the potential applicability of using LC and NC additives to enhance the early strength evolution and overall performance of UHPC.

Overall, this study has successfully quantified the effects of LC-NC additives on the mechanical properties and autogenous shrinkage of UHPC under normal temperature curing conditions, with the recommended optimum dosages being $0.075 \% \sim 0.1 \%$ LC and 3\% 4\% NC, respectively. Whilst the study results were plausible, exploration of new methods for further reducing shrinkage along with the need for correlation and validation with field performance data is warranted in future studies. Nonetheless, the study beneficially contributes to enriching the literature through the provision of a reference datum for quantifying the modification and enhancement effects of LC-NC additives on UHPC.

\section{Data Availability}

The data used to support the findings of this study are available from the corresponding author upon request.

\section{Disclosure}

The content of this paper, which is neither a standard nor a design/bidding document, reflects the views of the authors who are solely responsible for the facts and accuracy of the data presented herein and does not necessarily reflect the official views or policies of any institution. Trade names were used solely for information purposes and not for product endorsement, advertisement, or certification.

\section{Conflicts of Interest}

The authors declare that they have no conflicts of interest.

\section{Acknowledgments}

The authors thank the Department of Transportation of Hunan Province Traffic Science and Technology Project for the financial support in funding this study. 


\section{References}

[1] S. He, J. Qiu, J. Li, and E.-H. Yang, "Strain hardening ultrahigh performance concrete (SHUHPC) incorporating CNFcoated polyethylene fibers," Cement and Concrete Research, vol. 98, pp. 50-60, 2017.

[2] Y. Su, C. Wu, J. Li, Z.-X. Li, and W. Li, "Development of novel ultra-high performance concrete: from material to structure," Construction and Building Materials, vol. 135, pp. 517-528, 2017.

[3] S. Abbas, A. M. Soliman, and M. L. Nehdi, "Exploring mechanical and durability properties of ultra-high performance concrete incorporating various steel fiber lengths and dosages," Construction and Building Materials, vol. 75, pp. 429441, 2015.

[4] W. Chong, C. Yang, L. Fang et al., "Preparation of ultra-high performance concrete with common technology and materials," Cement \& Concrete Composites, vol. 26, no. 8, pp. 538-544, 2004.

[5] S. T. Kang, J. I. Choi, K. T. Koh et al., "Hybrid Effects of Steel fiber and microfiber on the tensile behavior of ultra-highperformance Concrete," Composite Structures, vol. 145, pp. 3-42, 2016.

[6] K. Wille, A. E. Naaman, S. El-Tawil, and G. J. Parra-Montesinos, "Ultra-high performance concrete and fiber reinforced concrete: achieving strength and ductility without heat curing," Materials and Structures, vol. 45, no. 3, pp. 309-324, 2012.

[7] P. Y. Blais and M. Couture, "Precast, prestressed pedestrian bridge-world's first reactive powder concrete structure," $P c i$ Journal, vol. 44, no. 5, 1999.

[8] M. Behloul and K. C. Lee, "Ductal seonyu footbridge," Structural Concrete, vol. 4, no. 4, pp. 195-201, 2003.

[9] E. Denarie and E. Bruhwiler, "Structural rehabilitation with ultra high performance fibre reinforced concretes," Restoration of buildings and monuments=Bauinstandsetzen und Baudenkmalpflege, vol. 12, no. 5, pp. 453-467, 2006.

[10] E. Denarié, SAMARIS D22-Full Scale Application of UHPFRC for the Rehabilitation of Bridges-From the Lab to the Field, Samaris, Brussels, Belgium, 2005.

[11] M. Bastien Masse and E. Brühwiler, "Concrete bridge deck slabs strengthened with UHPFRC," in Proceedings of the IABSE Conference Rotterdam 2013 "Assessment, Upgrading and Refurbishment of Infrastructures”, vol. 99, Rotterdam, Netherlands, May 2013.

[12] M. A. Sakr, A. A. Sleemah, T. M. Khalifa, and W. N. Mansour, "Shear strengthening of reinforced concrete beams using prefabricated ultra-high performance fiber reinforced concrete plates: experimental and numerical investigation," Structural Concrete, vol. 20, no. 3, pp. 1137-1153, 2019.

[13] O. Cornelius, E. Denarié, and E. Brühwiler, "UHPFRC protection layer on the crash barrier walls of a bridge," Advances in Construction Materials, vol. 3, pp. 203-210, 2007.

[14] E. Brühwiler and E. Denarié, "Rehabilitation and strengthening of concrete structures using ultra-high performance fibre reinforced concrete," Structural Engineering International, vol. 23, no. 4, pp. 450-457, 2013.

[15] T. Ono, "Application of ultra-high-strength fiber-reinforced concrete for irrigation channel repair works," in Designing And Building With UHPFRCWiley, Hoboken, NJ, USA, 2011.

[16] L. Guingot, D. Dekhil, and P. Soulier, "Strengthening of hydraulic structures with UHPC," in Proceedings of the RILEM-Fib-AFGC International Symposium on Ultra-high
Performance Fibre-Reinforced Concrete, pp. 137-146, Marseille, France, January 2013.

[17] Z. Huang, J. Fan, and X. Xie, "Research on the high performance and low-density aerated concrete," Materials Review, vol. 12, pp. 136-140, 2013.

[18] U. Sharma, L. P. Singh, B. Zhan, and C. S. Poon, "Effect of particle size of nanosilica on microstructure of C-S-H and its impact on mechanical strength," Cement and Concrete Composites, vol. 97, pp. 312-321, 2019.

[19] W. Li, Z. Huang, F. Cao, Z. Sun, and S. P. Shah, "Effects of nano-silica and nano-limestone on flowability and mechanical properties of ultra-high-performance concrete matrix," Construction and Building Materials, vol. 95, pp. 366-374, 2015.

[20] J. Camiletti, A. M. Soliman, and M. L. Nehdi, "Effects of nanoand micro-limestone addition on early-age properties of ultra-high-performance concrete," Materials and Structures, vol. 46, no. 6, pp. 881-898, 2013.

[21] L. R. Gurney, D. P. Bentz, T. Sato, and W. J. Weiss, "Reducing set retardation in high-volume fly ash mixtures with the use of limestone," Transportation Research Record: Journal of the Transportation Research Board, vol. 2290, no. 1, pp. 139-146, 2012.

[22] T. Sato and J. J. Beaudoin, "The effect of nano-sized $\mathrm{CaCo}_{3}$ addition on the hydration of opc containing high volumes of ground granulated blast-furnace slag," in Proceedings of theb2nd International RILEM Symposium on Advances in Concrete through Science and Engineering, Quebec City, Canada, September 2006.

[23] GB/T17671-1999, Test Method for Strength of Cement Mortar (IOS), Standards Press of China, Beijing, China, 1999.

[24] Z. Huang and F. Cao, "Effects of nano-materials on the performance of UHPC," Materials Review, vol. 18, pp. 136141, 2012.

[25] Z. Huang and T. Zu, "Influence of nano-CaCO3 on ultra highperformance concrete," Bulletin of the Chinese Ceramic Society, vol. 6, pp. 1103-1109, 2013.

[26] E. Kassem, L. Walubita, T. Scullion, E. Masad, and A. Wimsatt, "Evaluation of full-depth asphalt pavement construction using X-ray computed tomography and ground penetrating radar," Journal of Performance of Constructed Facilities, vol. 22, no. 6, pp. 408-416, 2008.

[27] L. F. Walubita, B. Jamison, A. E. Alvarez et al., "Air void characterisation of HMA gyratory laboratory-moulded samples and field cores using X-ray computed tomography (X-ray CT)," Journal of the South African Institution of Civil Engineering, vol. 54, no. 1, pp. 22-30, 2012.

[28] L. Xiao and H. Zhang, "Influence of new composite early strength agent on mechanical properties of concrete (mortar) and its mechanism analysis," Bulletin of the Chinese Ceramic Society, vol. 37, no. 7, pp. 2115-2119, 2018.

[29] B. Persson, "Self-desiccation and its importance in concrete technology," Materials and Structures, vol. 30, no. 5, pp. 293-305, 1997.

[30] E.-I. Tazawa and S. Miyazawa, "Influence of cement and admixture on autogenous shrinkage of cement paste," Cement and Concrete Research, vol. 25, no. 2, pp. 281-287, 1995. 